\title{
OPEN The relationship
}

\section{between metabolic syndrome and obstructive sleep apnea syndrome: a nationwide population-based study}

\author{
Do Hyun $\mathrm{Kim}^{1}$, Bongseong Kim², Kyungdo $\mathrm{Han}^{2 \bowtie}$ \& Soo Whan Kim ${ }^{1 凶}$
}

There has been a need for research on the association between metabolic syndrome (MetS) and obstructive sleep apnea syndrome (OSAS) using large data such as nationwide population-based data that adjusts important confounding factors. Therefore, we investigated the relationship between MetS and OSAS. The data source we used was the National Health Insurance Service claims database managed by the Republic of Korea government, in which 10,113,560 individuals were enrolled in 2009 and followed up until 2018. The independent association of MetS with the risk of OSAS was determined using a Cox proportional hazards model with adjustment for age, sex, smoking status, alcohol consumption, regular physical exercise, and body mass index. Our results showed that MetS were strongly associated to OSAS which was adjusted for several confounding factors. Also, we found men, increased waist circumference and increased triglyceride are important risk factors for OSAS.

Metabolic syndrome (MetS) comprises multiple cooccurring conditions that increase the risk of diabetes and cardiovascular disease, including abdominal obesity, high blood pressure, hyperglycemia, and dyslipidemia ${ }^{1-3}$. MetS was diagnosed based on the criteria proposed by the International Diabetes Federation, i.e., three of more of the five MetS components: high blood pressure ( $\mathrm{SBP} \geq 130 \mathrm{mmHg}, \mathrm{DBP} \geq 85 \mathrm{mmHg}$ ) or treatment for previously diagnosed hypertension, elevated triglyceride (TG) level ( $\geq 150 \mathrm{mg} / \mathrm{dL})$, low high-density lipoprotein cholesterol (HDL-C) level ( $<40 \mathrm{mg} / \mathrm{dL}$ for men and $<50 \mathrm{mg} / \mathrm{dL}$ for women), elevated fasting plasma glucose level ( $\geq 100 \mathrm{mg} / \mathrm{dL}$ ) or previously diagnosed type $2 \mathrm{DM}$, and abdominal obesity (waist circumference $\geq 90 \mathrm{~cm}$ for men and $\geq 85 \mathrm{~cm}$ for women $)^{4}$. Up to one billion middle aged people have OSAS worldwide ${ }^{5}$, and the number of OSAS patients has tended to increase along with the obesity epidemic ${ }^{6-8}$. Some conditions not classified as MetS components may nevertheless exacerbate cardiovascular disease in MetS patients, such as obstructive sleep apnea syndrome (OSAS). OSAS is considered one of the most significant sleep disorders, with a prevalence of $9-17 \%{ }^{9}$. It is a chronic respiratory condition, in which the air flow is repeatedly blocked during sleep, resulting in recurrent hypoxia, hypercapnia, and arousal ${ }^{10,11}$. OSAS can be both a sleep disorder and a heterogeneous metabolic disorder ${ }^{12}$. Meta-analyses have shown an association between MetS and OSAS ${ }^{13,14}$; however, many factors modulate the association of MetS with OSAS, making it difficult to assess the relationship between them with precision ${ }^{15-17}$; Also, no report on the association between the two diseases has adjusted for body mass index $(\mathrm{BMI})^{17}$. Also, it has been suggested that to investigate the association between MetS and OSAS, a study including a large population and adjusting for confounding factors is needed ${ }^{15}$.

Therefore, we conducted this study to evaluate the association between MetS and OSAS using nationwide population-based data. In addition, because the incidence of OSAS differs by gender, we also conducted analyses stratified according to this variable.

${ }^{1}$ Department of Otolaryngology-Head and Neck Surgery, Seoul St. Mary's Hospital, College of Medicine, The Catholic University of Korea, Banpo-daero 222, Seocho-gu, Seoul 137-701, Republic of Korea. ${ }^{2}$ Department of Statistics and Actuarial Science, Soongsil University, 369 Sangdo-ro, Dongjak-gu, Seoul 06978, Republic of Korea. ${ }^{\circledR}$ email: hkd917@naver.com; kshent@catholic.ac.kr 


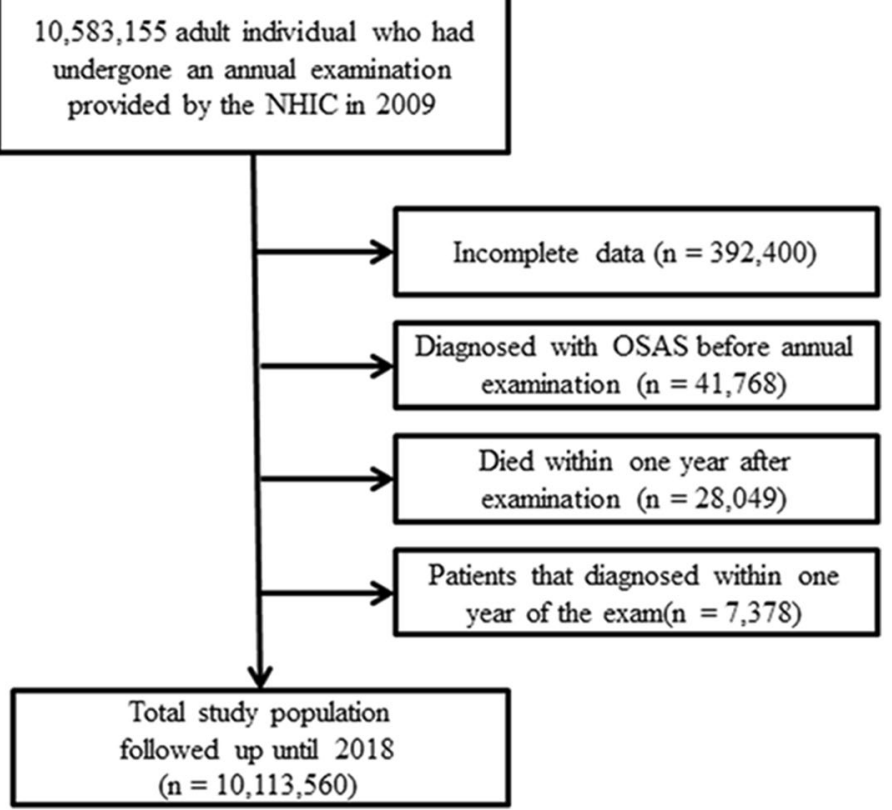

Figure 1. Flow chart of the study population.

\begin{abstract}
Materials and methods
Data sources and study population. Our data source was the National Health Insurance Service (NHIS) claims database (NHIS-2020-1-313), managed by the Republic of Korea government. We analyzed data for the period 2009-2018. In Korea, the NHIS offers health insurance to $97 \%$ of the population ${ }^{18}$. This study was approved by the Ethics Committee of the National Evidence-Based Healthcare Collaborating Agency, and the need for informed patient consent was waived. The NHIS reviews claims from both outpatients and inpatients, and holds data on diagnoses, procedures, prescriptions, and demographics. Claims from the Medical Assistance Program and the Medical Care for Patriots and Veterans Affairs Scheme, which cover medical expenses not reimbursed by the NHIS, are also reviewed by the latter body. Therefore, the entire Korean population is well represented by the NHIS database, which rules out selection bias. Because the NHIS deidentifies personal information to ensure anonymity, the institutional review board of Seoul Saint Mary's Hospital waived the requirement for informed consent for this study (KC19ZESI0560). All procedures were carried out in accordance with the Helsinki Declaration of 1964 and subsequent amendments or equivalent ethical standards. In 2009, $10,583,155$ adults (aged $>19$ years) were examined through annual checkups provided by the NHIC. Due to incomplete data, 392,400 cases were excluded from our analysis. To accurately calculate the incidence of OSAS, 41,768 patients diagnosed with OSAS before the annual examination, and 28,049 who died within 1 year of the examination, were also excluded, as were 7378 patients diagnosed within 1 year of the exam to preclude any effect of time differences in data collection on the results. Finally, a total of 10,113,560 individuals were analyzed and followed up until 2018 (Fig. 1).
\end{abstract}

Clinical parameters and diagnostic criteria. Baseline data were collected on the following variables associated with the risk of OSAS: age (years), alcohol consumption (in 1 week and on a single occasion; $30 \mathrm{~g} /$ day $=$ heavy drinkers ${ }^{19}$ ), income level, sex, and smoking status. The regular exercise has been defined as vigorous exercise at least 3 days a week or moderate exercise at least 5 days a week. BMI was calculated by dividing the subject's weight (kilograms) by the square of the subject's height (meters). According to the criteria for the AsiaPacific region, participants with a BMI $\geq 25 \mathrm{~kg} / \mathrm{m}^{2}$ were considered obese ${ }^{20}$. Diabetes mellitus (DM) was defined as International Classification of Disease 10th Revision (ICD-10) codes E11-14, plus at least one prescription of antidiabetic medication per year or a fasting glucose level $\geq 7 \mathrm{mmol} / \mathrm{L}$ (data obtained from the health database). Hypertension was indicated by a prescription (at least once a year) of a antihypertensive agent under ICD-10 codes I10-I15, or systolic blood pressure /diastolic blood pressure [SBP/DBP] $\geq 140 / 90 \mathrm{mmHg}{ }^{21}$. Dyslipidemia was indicated by ICD-10 code E78 along with at least one prescription of lipid-lowering agents per year, or total cholesterol $\geq 240 \mathrm{mg} / \mathrm{dL}^{22}$. OSAS was defined as G47.30 in ICD-10 code as previously reported ${ }^{23}$. The OSAS group comprised those with OSAS diagnosed between 2009 and $2018^{24,25}$. Abdominal obesity was classified based on the International Obesity Task Force Asia-Pacific region and the cutoffs for Korean adults proposed by the Korean Society for the Study of Obesity ${ }^{26}$.

Statistical analyses. To calculate the incidence of OSAS, the number of obstruction events was divided by the person-time at risk. The independent association of MetS with the risk of OSAS was determined using a Cox proportional hazards model adjusted for age, sex, smoking status, alcohol consumption, regular physical exer- 


\begin{tabular}{|c|c|c|c|}
\hline & Non-OSAS & OSAS & \multirow[b]{2}{*}{$p$-value } \\
\hline & $(n=10,038,900)$ & $(n=74,660)$ & \\
\hline Age (years) & $47.1 \pm 14.11$ & $44 \pm 11.85$ & $<0.0001$ \\
\hline Sex, male (n, [\%]) & $5,495,010(54.74)$ & $58,273(78.05)$ & $<0.0001$ \\
\hline Income, low $20 \%(\mathrm{n},[\%])$ & $1,757,833(17.51)$ & $10,228(13.7)$ & $<0.0001$ \\
\hline Current smoker (n, [\%]) & $2,626,362(26.16)$ & $25,928(34.73)$ & $<0.0001$ \\
\hline Heavy drinker ( $\geq 30 \mathrm{~g} /$ day) (n, [\%]) & $794,290(7.91)$ & $8675(11.62)$ & $<0.0001$ \\
\hline Regular exercise (n, [\%]) & $1,819,385(18.12)$ & $14,643(19.61)$ & $<0.0001$ \\
\hline Body mass index $\left(\mathrm{kg} / \mathrm{m}^{2}\right)$ & $23.69 \pm 3.44$ & $25.23 \pm 3.33$ & $<0.0001$ \\
\hline Diabetes mellitus (n, [\%]) & $876,900(8.74)$ & $5307(7.11)$ & $<0.0001$ \\
\hline Hypertension (n, [\%]) & $2,701,840(26.91)$ & $21,204(28.4)$ & $<0.0001$ \\
\hline Dyslipidemia (n, [\%]) & $1,820,905(18.14)$ & $15,583(20.87)$ & $<0.0001$ \\
\hline Total cholesterol (mg/dL) & $195.22 \pm 41.46$ & $198.56 \pm 39.24$ & $<0.0001$ \\
\hline Systolic blood pressure (mmHg) & $122.43 \pm 15.05$ & $123.61 \pm 13.86$ & $<0.0001$ \\
\hline Diastolic blood pressure $(\mathrm{mmHg})$ & $76.3 \pm 10.05$ & $77.79 \pm 9.89$ & $<0.0001$ \\
\hline HDL cholesterol (mg/dL) & $56.52 \pm 33.05$ & $53.03 \pm 27.21$ & $<0.0001$ \\
\hline LDL cholesterol (mg/dL) & $121.16 \pm 214.76$ & $124.99 \pm 241.95$ & $<0.0001$ \\
\hline Triglyceride $(\mathrm{mg} / \mathrm{dL})$ & $112.49(112.45-112.53)$ & $131.53(130.98-132.08)$ & $<0.0001$ \\
\hline Waist circumference $(\mathrm{cm})$ & $80.2 \pm 9.43$ & $84.61 \pm 8.86$ & $<0.0001$ \\
\hline
\end{tabular}

Table 1. Baseline characteristics of patients with OSAS and controls. OSAS: obstructive sleep apnea syndrome; LDL: low density lipoprotein; HDL: high density lipoprotein.

cise status, and BMI. Associations of single and combined MetS components with the risk of OSAS development were evaluated. All statistical analyses were performed using SAS software (version 9.4; SAS Institute, Cary, NC, USA) and a two-sided p-value $<0.05$ was considered statistically significant.

\section{Results}

The subjects were divided into two groups according to the presence or absence of MetS. The basic characteristics of the participants are shown in Table 1. The OSAS group was younger, male than female, less income, and higher rates of smoking and heavy drinkers. In addition, the OSAS group showed higher BMI, hypertension, dyslipidemia, higher total cholesterol, higher triglyceride, higher waist circumference, higher LDL cholesterol, and lower HDL cholesterol, indicating association with MetS. However, they exercised more regularly and had a lower incidence of DM. During 2009, 74,660 patients were newly diagnosed with OSAS (OSAS group). The OSAS group participants were younger, more likely to be male, had a lower income, and were more likely to be a current smoker, heavy drinker, and engage in regular exercise compared to the non-OSAS group. The OSAS group participants were more likely to have hypertension and dyslipidemia, and had a higher BMI, larger waist circumference, and higher levels of total cholesterol, low-density lipoprotein cholesterol (LDL-C) and TG. However, the non-OSAS group patients were more likely to have DM, and also had a lower HDL-C level. To further examine the relationship between OSAS and MetS, demographic data such as age, sex, and BMI, as well as smoking, drinking, and exercise status, were adjusted for in multivariable analysis.

Multivariable-adjusted analysis of the association between MetS and OSAS. The incidence rate of OSAS in the non-MetS and MetS groups was 0.82 and 1.16, respectively (Table 2). The incidence rate of OSAS peaked in men in their $30 \mathrm{~s}$ and in women in their $50 \mathrm{~s}$, which is when menopause begins (Fig. 2). The incidence rate of OSAS was higher in males, and the incidence probability of OSAS between the MetS and non-MetS population showed a significant difference between groups (log-rank test, $\mathrm{p}<0.0001$; Fig. 3). The hazard ratio (HR) for OSAS was 1.50 (95\% confidence interval [CI] 1.52-1.57) in the MetS group. The HR of OSAS was higher in males $(1.57 ; 95 \%$ CI $1.54-1.60)$ than females $(1.31 ; 95 \%$ CI $1.26-1.36)(\mathrm{p}<0.0001)$. The HR (95\% CI) for OSAS increased with the number of MetS components, being 1.25 (1.23-1.28), 1.52 (1.48-1.55), 1.83 (1.78-1.87), 2.11 (2.05-2.17) and 2.38 (2.28-2.48) for 1,2-5 components, respectively, after adjusting for age, sex, smoking status, alcohol consumption, exercise status, and BMI. Also, the HRs were higher in men with 1-5 MetS components (1.22 [1.19-1.25], 1.46 [1.43-1.50], 1.79 [1.74-1.84], 2.12 [2.05-2.19] and 2.50 [2.38-2.62], respectively)] than in women (1.25 [1.19-1.30], 1.48 [1.41-1.56], 1.62 [1.53-1.71], 1.68 [1.58-1.79] and 1.67 [1.53-1.83], respectively) (Table 2). The probability of OSAS increased as the number of MetS components increased, and with the passage of time (log-rank test, $\mathrm{p}<0.0001$; Fig. 4).

OSAS risk according to combinations of metabolic syndrome components. We analyzed the incidence rates and multivariable-adjusted HRs for OSAS according to combinations of MetS components. All five components were individually associated with an increased risk of OSAS. Increases in waist circumference (HR: 1.99; 95\% CI 1.90-2.08) and TG level (HR: 1.32; 95\% CI 1.28-1.37) were associated with a marked increase in the risk of OSAS (Table 3). For the waist circumference component, there was a remarkable difference between 


\begin{tabular}{|c|c|c|c|c|c|c|c|}
\hline & \multirow[b]{2}{*}{ Non-OSAS } & \multirow[b]{2}{*}{ OSAS } & \multirow[b]{2}{*}{ IR } & \multicolumn{3}{|c|}{ Hazard ratio $(95 \% \mathrm{CI})^{\mathrm{a}}$} & \multirow[b]{2}{*}{ p-value ${ }^{*}$} \\
\hline & & & & Total & Male & Female & \\
\hline \multicolumn{8}{|c|}{ MetS } \\
\hline $\mathrm{No}^{\mathrm{b}}$ & $7,569,064$ & 50,823 & 0.82 & 1 (reference) & 1 (reference) & 1 (reference) & \\
\hline Yes & $2,544,496$ & 23,837 & 1.16 & $1.50(1.52,1.57)$ & $1.57(1.54,1.60)$ & $1.31(1.26,1.36)$ & $<0.0001$ \\
\hline \multicolumn{8}{|c|}{ Number of components } \\
\hline 0 & $2,731,043$ & 14,760 & 0.65 & 1 (reference) & 1 (reference) & 1 (reference) & \\
\hline 1 & $2,732,770$ & 18,846 & 0.84 & $1.25(1.23,1.28)$ & $1.22(1.19,1.25)$ & $1.25(1.19,1.30)$ & \\
\hline 2 & $2,105,251$ & 17,217 & 1.00 & $1.52(1.48,1.55)$ & $1.46(1.43,1.50)$ & $1.48(1.41,1.56)$ & \\
\hline 3 & $1,440,026$ & 13,206 & 1.13 & $1.83(1.78,1.87)$ & $1.79(1.74,1.84)$ & $1.62(1.53,1.71)$ & \\
\hline 4 & 822,911 & 7906 & 1.19 & $2.11(2.05,2.17)$ & $2.12(2.05,2.19)$ & $1.68(1.58,1.79)$ & \\
\hline 5 & 281,559 & 2725 & 1.20 & $2.38(2.28,2.48)$ & $2.50(2.38,2.62)$ & $1.67(1.53,1.83)$ & \\
\hline$\geq 3$ & $2,544,496$ & 23,837 & 1.16 & $1.96(1.91,2.00)$ & $1.94(1.90,1.99)$ & $1.64(1.57,1.73)$ & $<0.0001$ \\
\hline
\end{tabular}

Table 2. Incidence rates and HRs of OSAS according to the number of MetS components, based on an adjusted multivariable analysis (for the period 2009-2018). IR; incidence rate (per 1,000), OSAS; obstructive sleep apnea syndrome, CI; confidence interval, MetS; metabolic syndrome. ${ }^{*} \mathrm{p}$ for interaction $<0.001$ between male and female. ${ }^{a}$ Adjusted for age, sex, smoking status, alcohol consumption, regular exercise, and body mass index. ${ }^{\mathrm{b}}$ Individuals who had $0-2$ of MetS components.

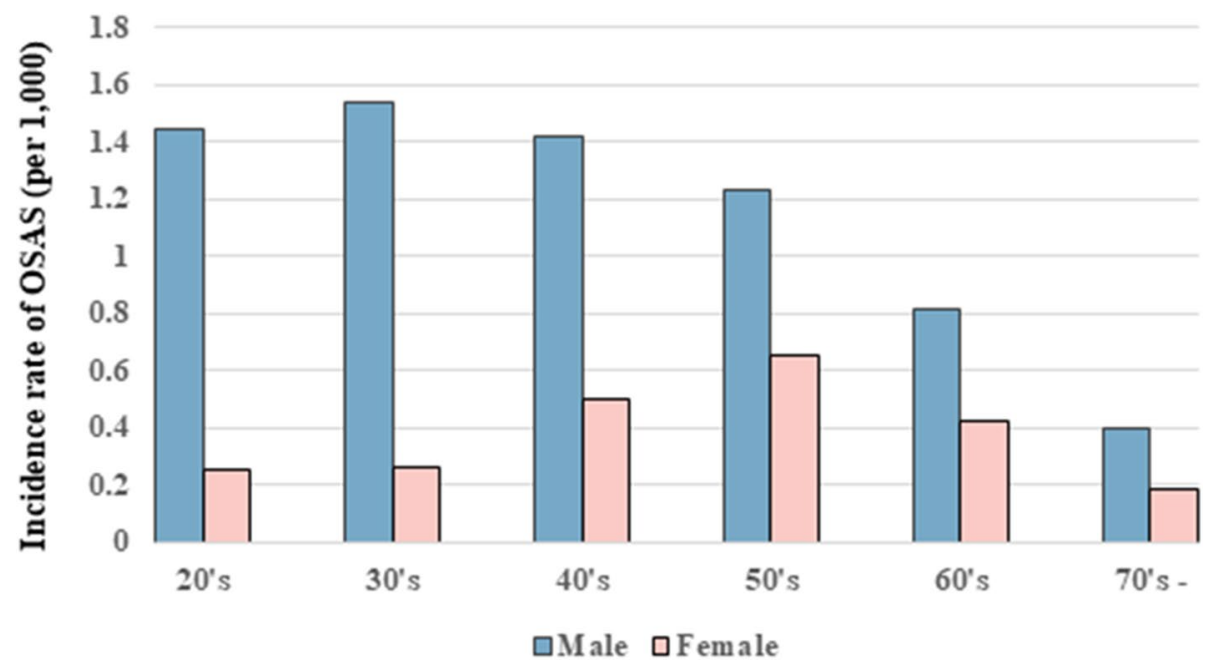

Figure 2. Incidence of OSAS according to age (for the 2009-2018).

men (HR: $2.00[1.90,2.10])$ and women (HR: 1.68 [1.52, 1.86]). Among those in whom the criterion for MetS (i.e., presence of $\geq 3$ of the 5 MetS components) was not met, there was a strong association of OSAS with waist circumference and TG level (HR: 2.22; 95\% CI 2.10-2.34). Among patients with three MetS components, the three components associated with the highest risk of OSAS were large waist circumference, high TG level, and high HDL-C level (HR: 2.68; 95\% CI 2.52-2.85). Among patients with four MetS components, the risk of OSAS was highest in those with the above combination plus hypertension (HR: 2.82; 95\% CI 2.70-2.95) (Table 3).

\section{Discussion}

The results of this nationwide Korean population-based study showed that MetS and the OSAS are closely related. The association was stronger in men than in women. Even when the criteria for MetS were not met, all individual MetS components were risk factors for OSAS, and the risk increased with the number of components. A large waist circumference and high TG level showed the strongest correlations with OSAS among the MetS components. Among patients with three or more MetS components, those with an elevated HDL-C and/or hypertension, accompanied by a large waist circumference and high TG level, showed a higher likelihood of OSAS.

Obesity is strongly associated with MetS and a well-known risk factor for OSAS ${ }^{27}$. As the proportion of obese people continues to rise, the link between OSAS and MetS has become increasingly apparent ${ }^{28}$. Simple obesity (based on BMI) should be adjusted for in analyses of the relationship between OSAS and MetS, as a major potential confounder ${ }^{14}$. Age, sex, income, smoking status, and alcohol consumption are other important confounders that should be adjusted for ${ }^{14,29}$, but many studies did not do this ${ }^{14}$. In this study, we tried to minimize confounding effects by adjusting for BMI, age, sex, smoking status, alcohol consumption, and exercise status. 


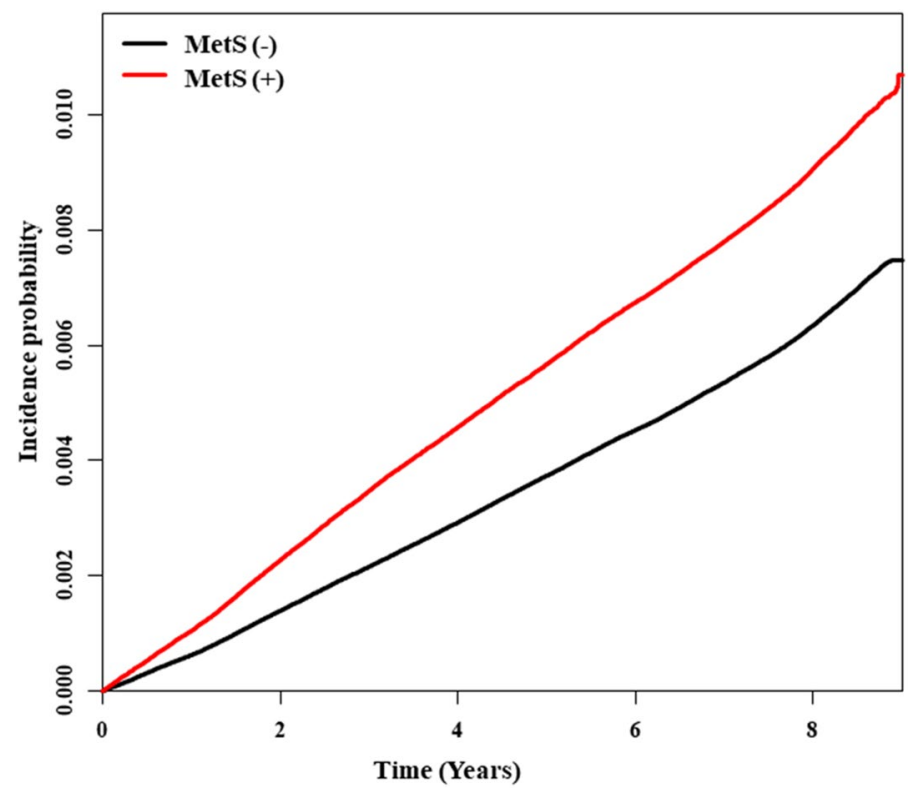

Figure 3. Incidence of OSA over the 10-year follow up period between MetS and non-MetS patients (log-rank test, $\mathrm{p}<0.0001)$.

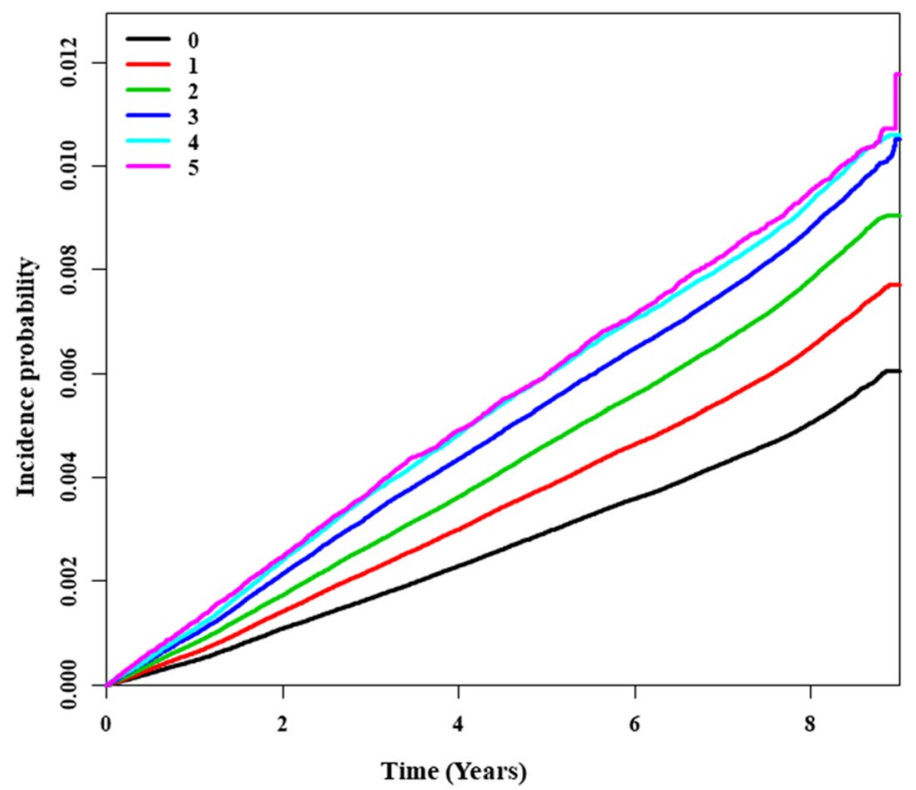

Figure 4. Incidence of OSA over the 10-year follow up period according to the numbers of MetS components (all components; log-rank test, $\mathrm{p}<0.0001$ ).

Abdominal obesity is different from simple obesity. Waist circumference mainly depends on the fatty tissue in the peritoneum (i.e., in the areas between the stomach, liver, kidneys, intestines and other organs). High levels of visceral fat were also observed in obese and metabolically obese normal weight people ${ }^{30}$. Visceral fat is now known to be a metabolically active tissue type, in which a large amount of proinflammatory substances and vasoactivators are produced ${ }^{31}$; these can cause metabolic dysregulation and atherogenesis. Also, serum leptin (adipocytokines) levels are considerably higher in patients with OSAS, suggesting that OSAS might be associated with leptin resistance ${ }^{32}$. Leptin resistance increases the likelihood of developing OSAS ${ }^{33}$. In addition to leptin resistance, abdominal obesity can cause systemic inflammation and metabolic dysfunction, leading to $\mathrm{OSAS}^{34}$. Compared to peripheral obesity, abdominal obesity has a greater effect on upper airway function ${ }^{35}$. Therefore, waist circumference should be measured as an important risk factor for OSAS. Visceral fat accounts for $5-8 \%$ of total body fat in women, and increases in menopause, while in men it accounts for $10-20 \%$ of total 


\begin{tabular}{|c|c|c|c|}
\hline & Total & Male & Female \\
\hline Combination & HR $(95 \% \mathrm{CI})^{\mathrm{a}}$ & HR $(95 \%$ CI $)+$ & HR $(95 \% \mathrm{CI})+$ \\
\hline Null & 1 (ref.) & 1 (ref.) & 1 (ref.) \\
\hline Glucose $\uparrow$ & $1.08(1.04,1.12)$ & $1.03(0.99,1.08)$ & $1.17(1.09,1.26)$ \\
\hline HBP & $1.19(1.15,1.22)$ & $1.13(1.09,1.16)$ & $1.25(1.17,1.33)$ \\
\hline $\mathrm{WC} \uparrow$ & $1.99(1.90,2.08)$ & $2.00(1.90,2.10)$ & $1.68(1.52,1.86)$ \\
\hline $\mathrm{TG} \uparrow$ & $1.32(1.28,1.37)$ & $1.27(1.23,1.32)$ & $1.32(1.19,1.47)$ \\
\hline $\mathrm{HDL} \downarrow$ & $1.16(1.11,1.22)$ & $1.19(1.11,1.27)$ & $1.16(1.09,1.24)$ \\
\hline Glucose $\uparrow / \mathrm{HBP}$ & $1.06(1.01,1.10)$ & $1.02(0.98,1.07)$ & $1.12(1.01,1.23)$ \\
\hline Glucose $\uparrow / \mathrm{WC} \uparrow$ & $1.89(1.76,2.02)$ & $1.86(1.72,2.01)$ & $1.75(1.49,2.06)$ \\
\hline Glucose $\uparrow / \mathrm{TG} \uparrow$ & $1.30(1.23,1.37)$ & $1.27(1.20,1.34)$ & $1.28(1.07,1.54)$ \\
\hline Glucose $\uparrow / \mathrm{HDL} \downarrow$ & $1.11(1.01,1.22)$ & $0.92(0.80,1.06)$ & $1.30(1.14,1.47)$ \\
\hline $\mathrm{HBP} / \mathrm{WC} \uparrow$ & $2.05(1.96,2.14)$ & $2.03(1.94,2.13)$ & $1.68(1.51,1.86)$ \\
\hline $\mathrm{HBP} / \mathrm{TG} \uparrow$ & $1.41(1.36,1.47)$ & $1.37(1.32,1.43)$ & $1.29(1.13,1.48)$ \\
\hline HBP/HDL $\downarrow$ & $1.42(1.33,1.52)$ & $1.30(1.18,1.42)$ & $1.38(1.25,1.52)$ \\
\hline $\mathrm{WC} \uparrow / \mathrm{TG} \uparrow$ & $2.22(2.10,2.34)$ & $2.20(2.08,2.32)$ & $1.58(1.28,1.93)$ \\
\hline $\mathrm{WC} \uparrow / \mathrm{HDL} \downarrow$ & $2.20(2.02,2.41)$ & $2.24(2.00,2.52)$ & $2.00(1.74,2.29)$ \\
\hline $\mathrm{TG} \uparrow / \mathrm{HDL} \downarrow$ & $1.76(1.69,1.83)$ & $1.63(1.55,1.72)$ & $1.82(1.68,1.96)$ \\
\hline Glucose $\uparrow / \mathrm{HBP} / \mathrm{WC} \uparrow$ & $1.87(1.78,1.98)$ & $1.91(1.80,2.02)$ & $1.47(1.29,1.67)$ \\
\hline Glucose $\uparrow / \mathrm{HBP} / \mathrm{TG} \uparrow$ & $1.20(1.15,1.26)$ & $1.18(1.12,1.24)$ & $1.25(1.05,1.47)$ \\
\hline Glucose $\uparrow / \mathrm{HBP} / \mathrm{HDL} \downarrow$ & $1.39(1.27,1.53)$ & $1.32(1.17,1.50)$ & $1.28(1.11,1.49)$ \\
\hline Glucose $\uparrow / \mathrm{WC} \uparrow / \mathrm{TG} \uparrow$ & $1.92(1.79,2.06)$ & $1.86(1.73,2.00)$ & $2.05(1.60,2.63)$ \\
\hline Glucose $\uparrow / \mathrm{WC} \uparrow / \mathrm{HDL} \downarrow$ & $1.88(1.62,2.19)$ & $1.93(1.59,2.34)$ & $1.66(1.30,2.11)$ \\
\hline Glucose $\uparrow / T G \uparrow / H D L \downarrow$ & $1.53(1.44,1.62)$ & $1.46(1.36,1.57)$ & $1.53(1.36,1.72)$ \\
\hline $\mathrm{HBP} / \mathrm{WC} \uparrow / \mathrm{TG} \uparrow$ & $2.38(2.28,2.48)$ & $2.35(2.24,2.45)$ & $1.70(1.44,2.01)$ \\
\hline $\mathrm{HBP} / \mathrm{WC} \uparrow / \mathrm{HDL} \downarrow$ & $2.19(2.01,2.39)$ & $2.31(2.07,2.58)$ & $1.67(1.44,1.93)$ \\
\hline $\mathrm{HBP} / \mathrm{TG} \uparrow / \mathrm{HDL} \downarrow$ & $1.89(1.81,1.97)$ & $1.80(1.71,1.89)$ & $1.73(1.60,1.87)$ \\
\hline $\mathrm{WC} \uparrow / \mathrm{TG} \uparrow / \mathrm{HDL} \downarrow$ & $2.68(2.52,2.85)$ & $2.70(2.53,2.90)$ & $2.08(1.81,2.38)$ \\
\hline Glucose $\uparrow / \mathrm{HBP} / \mathrm{WC} \uparrow / \mathrm{TG} \uparrow$ & $2.03(1.94,2.13)$ & $2.03(1.93,2.13)$ & $1.56(1.31,1.86)$ \\
\hline Glucose $\uparrow / \mathrm{BP} \uparrow / \mathrm{WC} \uparrow / \mathrm{HDL} \downarrow$ & $1.81(1.62,2.03)$ & $1.81(1.56,2.10)$ & $1.50(1.26,1.79)$ \\
\hline Glucose $\uparrow / \mathrm{BP} \uparrow / \mathrm{TG} \uparrow / \mathrm{HDL} \downarrow$ & $1.61(1.54,1.68)$ & $1.57(1.49,1.65)$ & $1.47(1.35,1.61)$ \\
\hline Glucose $\uparrow / \mathrm{WC} \uparrow / \mathrm{TG} \uparrow / \mathrm{HDL} \downarrow$ & $2.37(2.20,2.55)$ & $2.31(2.12,2.51)$ & $2.21(1.89,2.57)$ \\
\hline HBP/WC $\uparrow / T G \uparrow / H D L \downarrow$ & $2.82(2.70,2.95)$ & $2.94(2.80,3.09)$ & $1.93(1.76,2.13)$ \\
\hline All of 5 components & $2.33(2.23,2.43)$ & $2.43(2.31,2.54)$ & $1.67(1.53,1.83)$ \\
\hline
\end{tabular}

Table 3. Incidence rates and HRs of OSAS according to the presence of a combination of MetS components

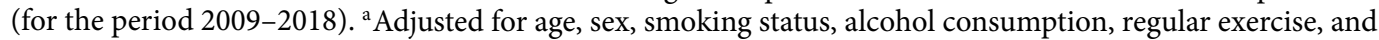
body mass index.

body fat ${ }^{36}$. Since the prevalence of abdominal obesity is higher in men than women, waist circumference can also be considered an important factor in the difference in incidence of OSAS between genders, and might also explain why the OSAS incidence is higher in menopausal women.

Recent studies have consistently demonstrated an independent association between adult OSAS and insulin resistance ${ }^{37-40}$. Insulin resistance sustains a low-grade inflammatory state, which can lead to upper airway narrowing, respiratory muscle fatigue, and decreased dilator muscle contraction ${ }^{34}$. The low success rate of continuous positive airway pressure treatment and upper airway surgery, for improving MetS or achieving weight loss in OSAS patients, may be explained by insulin resistance ${ }^{41-43}$.

There is considerable evidence that OSAS can lead to $\mathrm{MetS}^{44}$. Repeated respiratory obstruction events in OSAS result in intermittent hypoxia and frequent arousal. Temporarily ischemic tissue can release free radicals that cause oxidative stress, cytokine release and systematic inflammation ${ }^{45,46}$. Also, frequent arousal causes imbalances in the sympathetic nervous system and circadian misalignment. Consequently, intermittent hypoxia and the resultant oxidative stress, sympathetic activation, and sleep fragmentation have been suggested to underlie the pathogenic links between OSAS and glucose intolerance ${ }^{47}$, insulin resistance ${ }^{48}$, hypercholesterolemia ${ }^{49}$ and hyperlipidemia ${ }^{50}$, all of which are MetS components. As shown in the literature, Mets and OSAS share various pathologic mechanisms and together constitute a potentially pathologic vicious cycle.

Our research had both strength and limitations. This is the largest population-based study to date, with the NHIS database covering the entire Korean population. However, any study that uses claims data is associated with a risk of misclassification. Therefore, potential confounding factors may exist and affect the quality of data. However, these could be compensated with large population data and high HR. Also, although causality could 
not be inferred in this study, a high risk of OSAS was observed among MetS patients according to our analysis of a nationwide population-based dataset covering a 10 -year period.

\section{Conclusions}

OSAS is considered a major cause of MetS, and MetS can likewise trigger the development of OSAS. In this nationwide population-based analysis adjusted for several confounding factors, we confirmed the association of MetS components with OSAS. This is important because the coexistence of two pathologies within the same patient increases the levels of biomarkers, which directly contribute to, or increase the potential for, complications. Among the MetS components, particular attention should be paid to abdominal obesity in relation to OSAS, especially in men.

\section{Data availability}

The data that support the findings of this study are available from the Health Insurance Review \& Assessment Service (HIRA). Restrictions apply to the availability of these data, which were used under license for the current study, and so are not publicly available due to personal information protection. Data are available at https:// opendata.hira.or.kr/ with the permission of the HIRA.

Received: 8 February 2021; Accepted: 9 April 2021

Published online: 22 April 2021

\section{References}

1. Alberti, K. G. et al. Harmonizing the metabolic syndrome: A joint interim statement of the International Diabetes Federation Task Force on Epidemiology and Prevention; National Heart, Lung, and Blood Institute; American Heart Association; World Heart Federation; International Atherosclerosis Society; and International Association for the Study of Obesity. Circulation 120, 1640-1645. https://doi.org/10.1161/circulationaha.109.192644 (2009).

2. Alberti, K. G., Zimmet, P. \& Shaw, J. Metabolic syndrome-a new world-wide definition. A Consensus Statement from the International Diabetes Federation. Diabet. Med. 23, 469-480. https://doi.org/10.1111/j.1464-5491.2006.01858.x (2006).

3. Grundy, S. M., Brewer, H. B. Jr., Cleeman, J. I., Smith, S. C. Jr. \& Lenfant, C. Definition of metabolic syndrome: Report of the National Heart, Lung, and Blood Institute/American Heart Association conference on scientific issues related to definition. Arterioscler. Thromb. Vasc. Biol. 24, e13-18. https://doi.org/10.1161/01.Atv.0000111245.75752.C6 (2004).

4. Alberti, K. G., Zimmet, P. \& Shaw, J. The metabolic syndrome-a new worldwide definition. Lancet 366, 1059-1062. https://doi. org/10.1016/s0140-6736(05)67402-8 (2005).

5. Benjafield, A. V. et al. Estimation of the global prevalence and burden of obstructive sleep apnoea: A literature-based analysis. Lancet Respir. Med. 7, 687-698. https://doi.org/10.1016/s2213-2600(19)30198-5 (2019).

6. Li, R. et al. Prevalence of metabolic syndrome in Mainland China: A meta-analysis of published studies. BMC Public Health 16, 296. https://doi.org/10.1186/s12889-016-2870-y (2016).

7. McCullough, A. J. Epidemiology of the metabolic syndrome in the USA. J. Dig. Dis. 12, 333-340. https://doi.org/10.1111/j.17512980.2010.00469.x (2011).

8. Pan, W. H., Yeh, W. T. \& Weng, L. C. Epidemiology of metabolic syndrome in Asia. Asia Pac. J. Clin. Nutr. 17(Suppl 1), 37-42 (2008).

9. Peppard, P. E. et al. Increased prevalence of sleep-disordered breathing in adults. Am. J. Epidemiol. 177, 1006-1014. https://doi. org/10.1093/aje/kws342 (2013)

10. Drager, L. F., Togeiro, S. M., Polotsky, V. Y. \& Lorenzi-Filho, G. Obstructive sleep apnea: A cardiometabolic risk in obesity and the metabolic syndrome. J. Am. Coll. Cardiol. 62, 569-576. https://doi.org/10.1016/j.jacc.2013.05.045 (2013).

11. Malhotra, A. \& White, D. P. Obstructive sleep apnoea. Lancet 360, 237-245. https://doi.org/10.1016/s0140-6736(02)09464-3 (2002).

12. Gileles-Hillel, A., Kheirandish-Gozal, L. \& Gozal, D. Biological plausibility linking sleep apnoea and metabolic dysfunction. Nat. Rev. Endocrinol. 12, 290-298. https://doi.org/10.1038/nrendo.2016.22 (2016).

13. Qian, Y. et al. Obstructive sleep apnea predicts risk of metabolic syndrome independently of obesity: A meta-analysis. Arch. Med. Sci. 12, 1077-1087. https://doi.org/10.5114/aoms.2016.61914 (2016).

14. Xu, S. et al. The association between obstructive sleep apnea and metabolic syndrome: A systematic review and meta-analysis. BMC Pulm. Med. 15, 105. https://doi.org/10.1186/s12890-015-0102-3 (2015).

15. Carneiro, G., Fontes, F. H. \& Togeiro, S. M. Metabolic consequences of untreated obstructive sleep apnea syndrome. J. Bras. Pneumol. 36(Suppl 2), 43-46. https://doi.org/10.1590/s1806-37132010001400012 (2010).

16. Lam, J. C. \& Ip, M. S. An update on obstructive sleep apnea and the metabolic syndrome. Curr. Opin. Pulm. Med. 13, 484-489. https://doi.org/10.1097/MCP.0b013e3282efae9c (2007).

17. Papanas, N. et al. Predictors of obstructive sleep apnea in males with metabolic syndrome. Vasc. Health Risk. Manag. 6, 281-286. https://doi.org/10.2147/vhrm.s7948 (2010).

18. Lee, J., Lee, J. S., Park, S. H., Shin, S. A. \& Kim, K. Cohort profile: The National Health Insurance Service-National Sample Cohort (NHIS-NSC), South Korea. Int. J. Epidemiol. 46, e15. https://doi.org/10.1093/ije/dyv319 (2017).

19. Choi, J. Y. et al. Characteristics of metabolically obese, normal-weight women differ by menopause status: The Fourth Korea National Health and Nutrition Examination Survey. Menopause 20, 85-93. https://doi.org/10.1097/gme.0b013e31825d26b6 (2013).

20. James, P. T., Leach, R., Kalamara, E. \& Shayeghi, M. The worldwide obesity epidemic. Obes. Res. 9(Suppl 4), 228s-233s. https:// doi.org/10.1038/oby.2001.123 (2001).

21. Koo, B. K., Lee, C. H., Yang, B. R., Hwang, S. S. \& Choi, N. K. The incidence and prevalence of diabetes mellitus and related atherosclerotic complications in Korea: A National Health Insurance Database Study. PLoS ONE 9, e110650. https://doi.org/10.1371/ journal.pone.0110650 (2014).

22. Choi, E.-K. Cardiovascular research using the Korean National Health Information Database. Korean Circ. J. 50, $754-772$ (2020).

23. Lee, E. J., Suh, J. D. \& Cho, J. H. The incidence of prostate cancer is increased in patients with obstructive sleep apnea: Results from the national insurance claim data 2007-2014. Medicine 100, e24659. https://doi.org/10.1097/md.0000000000024659 (2021).

24. Choi, J. H., Kim, S. Y., Han, K. D. \& Cho, J. H. The incidence of non-Hodgkin lymphoma is increased in patients with obstructive sleep apnea. Leuk. Res. 98, 106455. https://doi.org/10.1016/j.leukres.2020.106455 (2020).

25. Choi, J. H., Lee, J. Y., Han, K. D., Lim, Y. C. \& Cho, J. H. Association between obstructive sleep apnoea and breast cancer: The Korean National Health Insurance Service Data 2007-2014. Sci. Rep. 9, 19044. https://doi.org/10.1038/s41598-019-55551-7 (2019).

26. Lee, S. Y. et al. Appropriate waist circumference cutoff points for central obesity in Korean adults. Diabetes Res. Clin. Pract. 75, 72-80. https://doi.org/10.1016/j.diabres.2006.04.013 (2007). 
27. Young, T. et al. Predictors of sleep-disordered breathing in community-dwelling adults: The Sleep Heart Health Study. Arch. Intern. Med. 162, 893-900. https://doi.org/10.1001/archinte.162.8.893 (2002).

28. Lam, J. C., Mak, J. C. \& Ip, M. S. Obesity, obstructive sleep apnoea and metabolic syndrome. Respirology 17, 223-236. https://doi. org/10.1111/j.1440-1843.2011.02081.x (2012).

29. Papadopoulos, D., Kikemeni, A., Skourti, A. \& Amfilochiou, A. The influence of socio-economic status on the severity of obstructive sleep apnea: A cross-sectional observational study. Sleep Sci. 11, 92-98. https://doi.org/10.5935/1984-0063.20180018 (2018).

30. Klitgaard, H. B., Kilbak, J. H., Nozawa, E. A., Seidel, A. V. \& Magkos, F. Physiological and lifestyle traits of metabolic dysfunction in the absence of obesity. Curr. Diab. Rep. 20, 17. https://doi.org/10.1007/s11892-020-01302-2 (2020).

31. Fantuzzi, G. Adipose tissue, adipokines, and inflammation. J. Allergy Clin. Immunol. 115, 911-919. https://doi.org/10.1016/j.jaci. 2005.02.023 (2005) (quiz 920).

32. McArdle, N., Hillman, D., Beilin, L. \& Watts, G. Metabolic risk factors for vascular disease in obstructive sleep apnea: A matched controlled study. Am. J. Respir. Crit. Care Med. 175, 190-195. https://doi.org/10.1164/rccm.200602-270OC (2007).

33. Castaneda, A., Jauregui-Maldonado, E., Ratnani, I., Varon, J. \& Surani, S. Correlation between metabolic syndrome and sleep apnea. World J. Diabetes 9, 66-71. https://doi.org/10.4239/wjd.v9.i4.66 (2018).

34. Gaines, J., Vgontzas, A. N., Fernandez-Mendoza, J. \& Bixler, E. O. Obstructive sleep apnea and the metabolic syndrome: The road to clinically-meaningful phenotyping, improved prognosis, and personalized treatment. Sleep Med. Rev. 42, 211-219. https://doi. org/10.1016/j.smrv.2018.08.009 (2018).

35. Schwab, R. J. et al. Identification of upper airway anatomic risk factors for obstructive sleep apnea with volumetric magnetic resonance imaging. Am. J. Respir. Crit. Care Med. 168, 522-530. https://doi.org/10.1164/rccm.200208-866OC (2003).

36. Wajchenberg, B. L. Subcutaneous and visceral adipose tissue: Their relation to the metabolic syndrome. Endocr. Rev. 21, 697-738. https://doi.org/10.1210/edrv.21.6.0415 (2000).

37. Ip, M. \& Mokhlesi, B. Sleep and glucose intolerance/diabetes mellitus. Sleep Med. Clin. 2, 19-29. https://doi.org/10.1016/j.jsmc. 2006.12.002 (2007).

38. Punjabi, N. M., Ahmed, M. M., Polotsky, V. Y., Beamer, B. A. \& O’Donnell, C. P. Sleep-disordered breathing, glucose intolerance, and insulin resistance. Respir. Physiol. Neurobiol. 136, 167-178. https://doi.org/10.1016/s1569-9048(03)00079-x (2003).

39. Punjabi, N. M. \& Polotsky, V. Y. Disorders of glucose metabolism in sleep apnea. J. Appl. Physiol. 1985(99), 1998-2007. https:// doi.org/10.1152/japplphysiol.00695.2005 (2005).

40. Punjabi, N. M. et al. Sleep-disordered breathing, glucose intolerance, and insulin resistance: The Sleep Heart Health Study. Am. J. Epidemiol. 160, 521-530. https://doi.org/10.1093/aje/kwh261 (2004).

41. Chirinos, J. A. et al. CPAP, weight loss, or both for obstructive sleep apnea. N. Engl. J. Med. 370, 2265-2275. https://doi.org/10. 1056/NEJMoa1306187 (2014).

42. Hoyos, C. M. et al. Cardiometabolic changes after continuous positive airway pressure for obstructive sleep apnoea: A randomised sham-controlled study. Thorax 67, 1081-1089. https://doi.org/10.1136/thoraxjnl-2011-201420 (2012).

43. Li, X. et al. Excessive daytime sleepiness, metabolic syndrome, and obstructive sleep apnea: Two independent large cross-sectional studies and one interventional study. Respir. Res. 20, 276. https://doi.org/10.1186/s12931-019-1248-y (2019).

44. Song, S. O. et al. Metabolic consequences of obstructive sleep apnea especially pertaining to diabetes mellitus and insulin sensitivity. Diabetes Metab. J. 43, 144-155. https://doi.org/10.4093/dmj.2018.0256 (2019).

45. Lavie, L. \& Polotsky, V. Cardiovascular aspects in obstructive sleep apnea syndrome-molecular issues, hypoxia and cytokine profiles. Respiration 78, 361-370. https://doi.org/10.1159/000243552 (2009).

46. Pialoux, V. et al. Effects of exposure to intermittent hypoxia on oxidative stress and acute hypoxic ventilatory response in humans. Am. J. Respir. Crit. Care Med. 180, 1002-1009. https://doi.org/10.1164/rccm.200905-0671OC (2009).

47. Lavie, L. Oxidative stress-a unifying paradigm in obstructive sleep apnea and comorbidities. Prog. Cardiovasc. Dis. 51, 303-312. https://doi.org/10.1016/j.pcad.2008.08.003 (2009).

48. Polotsky, V. Y. et al. Intermittent hypoxia increases insulin resistance in genetically obese mice. J. Physiol. 552, 253-264. https:// doi.org/10.1113/jphysiol.2003.048173 (2003).

49. Li, J., Nanayakkara, A., Jun, J., Savransky, V. \& Polotsky, V. Y. Effect of deficiency in SREBP cleavage-activating protein on lipid metabolism during intermittent hypoxia. Physiol. Genomics 31, 273-280. https://doi.org/10.1152/physiolgenomics.00082.2007 (2007).

50. Li, J. et al. Hyperlipidemia and lipid peroxidation are dependent on the severity of chronic intermittent hypoxia. J. Appl. Physiol. 1985(102), 557-563. https://doi.org/10.1152/japplphysiol.01081.2006 (2007).

\section{Author contributions}

Conceptualization, D.H.K. and S.W.K.; data curation, K.H. and B.K.; formal analysis, K.H. and B.K; Resources, D.H.K. and S.W.K.; supervision, D.H.K. and S.W.K.; writing-original draft, D.H.K.; writing-review and editing, D.H.K., K.H., B.K. and S.W.K.

\section{Competing interests}

The authors declare no competing interests.

\section{Additional information}

Correspondence and requests for materials should be addressed to K.H. or S.W.K.

Reprints and permissions information is available at www.nature.com/reprints.

Publisher's note Springer Nature remains neutral with regard to jurisdictional claims in published maps and institutional affiliations.

Open Access This article is licensed under a Creative Commons Attribution 4.0 International License, which permits use, sharing, adaptation, distribution and reproduction in any medium or format, as long as you give appropriate credit to the original author(s) and the source, provide a link to the Creative Commons licence, and indicate if changes were made. The images or other third party material in this article are included in the article's Creative Commons licence, unless indicated otherwise in a credit line to the material. If material is not included in the article's Creative Commons licence and your intended use is not permitted by statutory regulation or exceeds the permitted use, you will need to obtain permission directly from the copyright holder. To view a copy of this licence, visit http://creativecommons.org/licenses/by/4.0/.

(C) The Author(s) 2021 